\title{
Cenas da diversidade no ambiente empresarial: os atuais fluxos migratórios internacionais para 0 Brasil e o desafio da interculturalidade
}

Scenes of diversity in the business environment: current international migration flows to Brazil and the challenge of the interculturality

Escenas de la diversidad en el ambiente empresarial: los actuales flujos migratorios internacionales hacia Brasil y el desafío de la interculturalidad

(9) Wellington Teixeira Lisboa

- Doutorando em Sociologia na Universidade Estadual de Campinas (Unicamp)

- Mestre em Ciências da Comunicação pela Universidade de Coimbra, Portugal

- Bacharel em Relações Públicas, pela Universidade Católica de Santos (Unisantos)

- Docente da Unisantos

- Pesquisador das cátedras Sérgio Vieira de Mello e Giusfredo Santini, da Unisantos

- E-mail:wtlisboa@yahoo.com.br 


\section{Resumo}

O Brasil vem despontando como um dos destinos dos fluxos de trabalhadores e outros migrantes internacionais, desde a transição para o corrente século. Esse movimento desencadeia a recomposição de equipes de funcionários não apenas em corporações multinacionais ou globais atuantes no país, mas também nas empresas nacionais de médio e grande porte que passaram a empregar profissionais estrangeiros. Nesse cenário, esta reflexão focaliza a centralidade da cultura e da comunicação institucionais como vias estratégicas para a promoção do diálogo intercultural no ambiente empresarial.

\section{PALAVRAS-CHAVE: IMIGRAÇÃO • GLOBALIZAÇÃO •INTERCULTURALIDADE • COMUNICAÇÃO INTERNA.}

\section{Abstract}

Brazil is emerging as one of the destinations of the flows of workers and other international migrants, since the transition to the current century. This movement gives rise to rearrangement of teams of employees not only in multinational or global corporations in Brazil, but also in medium and large Brazilian companies which began to hire foreign professionals. In this scenario, this reflection focuses on the centrality of the culture and on the institutional communication as strategic means for sponsorship of intercultural dialogue in the business environment.

\section{KEYWORDS: IMMIGRATION • GLOBALIZATION •INTERCULTURALITY •INTERNAL COMMUNICATION.}

\section{Resumen}

Brasil está surgiendo como uno de los destinos de los flujos de trabajadores y otros migrantes internacionales desde el comienzo de este siglo. Este movimiento desencadena la recomposición de los equipos de funcionarios no sólo en las corporaciones multinacionales o globales que actúan en el Brasil, sino también en las empresas nacionales de medio y grande porte que pasaron a emplear a profesionales extranjeros. En este escenario, esta reflexión está dirigida a la centralidad de la cultura y de la comunicación institucional como vías estratégicas para la promoción del diálogo intercultural en el ambiente empresarial. 


\section{ANO 11 • NÚMERO $21 \cdot 2$ - SEM. 2014 • ORGANICOM \\ CENAS DA DIVERSIDADE NO AMBIENTE EMPRESARIAL: OS ATUAIS FLUXOS MIGRATÓRIOS INTERNACIONAIS PARA O BRASIL E O DESAFIO DA INTERCULTURALIDADE}

$\mathrm{H}$

á pouco mais de duas décadas, grande volume de brasileiros partiu de suas cidades de residência a destinos estrangeiros os mais diversos, em geral para o Paraguai, o Japão, os Estados Unidos ou países situados no continente europeu, sobretudo Portugal, Espanha, Inglaterra, Itália, em busca de melhores condições de vida e da possibilidade imaginária de concretização de seus projetos pessoais e/ou familiares, em curto ou longo prazo (Sales, 1992; Patarra, 2005). Nos últimos anos, inversamente, o Brasil vem despontando como uma das nações ocidentais inseridas na rota dos fluxos de trabalhadores e outros tipos de migrantes internacionais, também como polo de atração.

Diversosfatores de ordem conjuntural e estrutural, sobretudo os alusivos à sua recente estabilidade econômica, vêm contribuindo para a notoriedade desse país como um dos destinos prioritários de distintos fluxos humanos, oriundos dos continentes europeu e americano, com destaque para os portugueses (Lang; Campos, 2012), espanhóis, bolivianos (Baeninger, 2012), peruanos, haitianos (Oliveira e Moreira, 2013; Cogo, 2014), mas também provenientes dos países africanos (Desidério, 2005) e asiáticos (Baeninger, 2013; Peres e Baeninger, 2013), a exemplo dos senegaleses, angolanos, moçambicanos, coreanos, chineses, entre outros.

0 relativo adensamento dos processos democráticos nacionais e o fortalecimento de suas instituições representativas; 0 estreitamento das relações diplomáticas brasileiras com nações e blocos político-econômicos regionais, como o Mercado Comum do Sul (Mercosul) (Souchaud; Fusco, 2008), a União de Nações Sul-Americanas (Unasul), a Comunidade dos Países de Língua Portuguesa (CPLP) e o grupo dos Brics (Dwyer, 2011); o desenvolvimento acadêmico e científico e as parcerias na esfera educacional; as articulações empresariais em torno do mercado das tecnologias, do turismo e dos megaeventos, da engenharia civil, dos transportes, da exploração de petróleo e das demais fontes de energia, da infraestrutura e logística portuária, entre outros segmentos, parecem vir contribuindo com a inserção do Brasil no circuito dos deslocamentos geográficos de trabalhadores e outros migrantes internacionais, para não dizer das variáveis explicativas concernentes às filiações históricoculturais mantidas entre os países e, ainda, aquelas específicas ao trânsito de refugiados. 0 contínuo aparelhamento das médias e grandes cidades, num processo ascendente de urbanização e de dinamismo das regiões metropolitanas (Baeninger, 2013), que se remodelam na tentativa de se inserirem e corresponderem, estrategicamente, às demandas financeiras globais, também deve ser enfocado como um dos vetores que sustenta a entrada do Brasil no conjunto de países para onde, no corrente século, convergem fluxos de capitais, de mercadorias e equipamentos, de projetos em rede (Castells, 2007) e, igualmente, de pessoas.

Nesse cenário brasileiro (e não apenas) de reconstituição de suas bases econômicas e de sua força humana de trabalho, a mobilidade do capital internacional coloca-se como um dos importantes articuladores da redistribuição de populações no seu território. Em linhas gerais, equivale a dizer que a rotatividade do capital na geografia do sistema-mundo, tal como o designa Immanuel Wallerstein (2004), impulsiona o trânsito de mão de obra, com e sem qualificação, boa parte a custo bem baixo, para que sejam suportadas as atividades produtivas desencadeadas em pontos esparsos do planeta, de modo a assegurar condições favoráveis para a sua reprodução em tantas outras localidades transformadas, ou em vias de mutação, para atender a semelhantes demandas.

Sob múltiplos aspectos, o êxito e a expansão do capital reivindicam a circulação de trabalhadores (Tarrius, 2002), mais particularmente da "classe-que-vive-do trabalho" (Antunes, 2009), e a existência ou mesmo a ligeira e audaciosa criação de novos espaços de acumulação de riquezas. Muitas vezes até se apela a artifícios de criação de simulacros ancorados em desejos e fantasias (burguesas) socialmente compartilhados, ofertando empreendimentos "vocacionados", sobretudo, ao entretenimento e lazer, como clubes, resorts, ilhas artificiais e parques temáticos, no interior dos quais a referência a tempo 


\section{ANO 11 • NÚMERO $21 \cdot 2$ - SEM. 2014 • ORGANICOM \\ CENAS DA DIVERSIDADE NO AMBIENTE EMPRESARIAL: OS ATUAIS FLUXOS MIGRATÓRIOS INTERNACIONAIS PARA O BRASIL E O DESAFIO DA INTERCULTURALIDADE}

180

e localidade também se torna obscura e transitória (Bauman, 2003; Harvey, 2005). A divisão internacional do trabalho, nesse sentido, pressiona o deslocamento humano e a emergência de cidades e países que funcionam como receptáculos dinâmicos de fluxos econômicos e populacionais em escala inter e/ou transnacional.

É essa conjuntura contemporânea que, precisamente, compõe o eixo fundamental a partir do qual a presente reflexão se delineia. Considerando o crescente volume de estrangeiros que passou a residir no Brasil nos últimos anos (IBGE, 2014), dando continuidade a suas trajetórias de trabalho e às suas narrativas de vida num país latino-americano cujas condições estruturais vêm passando por profunda reconfiguração, novos desafios e oportunidades se colocam à dinâmica dos relacionamentos interpessoais processados nos ambientes organizacionais. Como corolário, aos profissionais que atuam na gestão da comunicação interna, distintas estratégias devem ser revistas e pensadas no sentido de dirimir ruídos de comunicação e estranhamentos derivados dos contatos interculturais, compulsórios ou não, vivificados no cenário das empresas brasileiras ou das corporações estrangeiras que atuam no território nacional. Neste texto de caráter teórico e introdutório sobre o tema, 0 campo da comunicação organizacional, em especial da comunicação interna, será perspectivado, na sua trama de articulações, sob a condicionante referente à demanda proporcionada pelo conjunto de sujeitos de nacionalidades diversas que constituem e revigoram a produção de cultura e de sentido no ambiente compósito das organizações.

\section{PAISAGENS EMPRESARIAIS MULTIFACES E OS DESAFIOS COMUNICACIONAIS}

A inserção do Brasil na rota das migrações internacionais contemporâneas explica-se, entre outros fatores de âmbito geográfico e os concernentes à política interna, pela reconfiguração econômica mundial em processamento desde a década de 1990. Saskia Sassen (2010) acentua a necessidade de analisar esse fenômeno populacional levando-se em conta os trânsitos econômicos em escala global, já que a nova fase "líquida" (Bauman, 2003) de acumulação capitalista pressupõe negociações financeiras estabelecidas em espaços móveis, voláteis, cuja funcionalidade adequa-seà mobilidade do capital e da mão de obra. Essa socióloga atenta para a recente profusão das "cidades globais" em praticamente todos os continentes, metrópoles, de ininterruptos fluxos, que são ditadas (e dilatadas) por interesses concentrados do mercado e que emergiram tão rapidamente que acabaram por despoletar alterações inéditas, por vezes inestimadas, nas paisagens urbanas e nas estatísticas demográficas e setoriais locais.

Sob um ponto de vista antropológico, Arjun Appadurai (2004) complementa esse panorama ao referir que 0 arcabouço de riquezas, indivíduos, produtos, imagens que se desloca nos cenários globais contemporâneos, movimento amparado pela própria relocalização do capital e do trabalho, fomenta o aparecimento de paisagens modernas com certas peculiaridades do que ele denomina como sendo "financiopaisagens" e "etnopaisagens". Ao propor o primeiro conceito, esse autor sublinha que, atualmente, a disposição do capital estabelece um território de negociações empresariais volúvel, enigmático e muito mais complexo do que se pode conceber, posto que os mercados de capitais, as bolsas financeiras nacionais e estrangeiras e a especulação comercial movem-se a uma velocidade estonteante, driblando ou até mesmo fustigando todo tipo de demarcação fronteiriça. Quanto ao último, a noção de "etnopaisagens", esse antropólogo faz menção aos cenários exponencialmente representados pela figura dos imigrantes, esses que, com efeito, são um dos protagonistas na conformação de profundas e estruturantes metamorfoses sociais desencadeadas, em especial, nos espaços públicos das médias e grandes cidades. 


\section{ANO 11 • NÚMERO $21 \cdot 2$ @ SEM. 2014 • ORGANICOM \\ CENAS DA DIVERSIDADE NO AMBIENTE EMPRESARIAL:

Ao circularem pelas ruas, praças, comércios; ao utilizarem os transportes públicos, os equipamentos e espaços de lazer; ao acessarem os serviços públicos e privados básicos à tessitura material e simbólica da vida cotidiana; ao inscreverem seus traços identitários nas associações de interesse comum e/ou em territórios específicos, os denominados territórios étnicos (Paiva, 2011); ao dispenderem sua força de trabalho nas empresas situadas no país para onde migraram, esses sujeitos promovem e provocam o delineio de panoramas humanos diversificados, que se mesclam aos circuitos financeiros internacionais e/ou globais. No intuito de ligeiramente exemplificarmos a conexão entre as "financiopaisagens" e as "etnopaisagens", recorremos a pesquisadores como Luiz F. Lampreia (2003) e Alice B. Lang e Maria C. S. de Campos (2012), que avaliam os fluxos financeiros do capital português ao Brasil e atestam sua direta vinculação aos deslocamentos de profissionais daquela nacionalidade europeia a este país latinoamericano, nos últimos anos. Por sua vez, Ismara I. de Souza (2006) e Bruno Ayllón Pino (2006) pontuam o aumento da emigração de espanhóis ao Brasil desde 1990, quando se intensificaram os trânsitos, de lá para cá, de poderosas empresas dos mais diversos segmentos, do ramo da hotelaria ao da prestação de serviços de telefonia, em todo o território nacional.

Como sujeitos reterritorializados (Haesbert, 2004) ou em incessante circulação (Tarrius, 2002), esses imigrantes trabalhadores transformaram-se em personagens arquetípicos das urbes modernas, assim como de muitas empresas multinacionais e/ou globais nelas alocadas. Isso porque, entre outros motivos, parte considerável das populações não pode escapar do irreversível esgotamento do ciclo de produção e do desenvolvimento econômico orientado sob o modelo fordista até então imperante, colapso que originou o paradigma da flexibilidade dos processos de produção e consumo e da própria dinâmica em torno do mercado de trabalho. A acumulação flexível, que a passos largos tornou-se o modelo por excelência com base no qual, na virada do século XX para o XXI, seria possível suplantar a crise estrutural global do capital (Antunes, 2009), passou a instituir diretrizes fundantes às lógicas de desenvolvimento no mundo, criando, por exemplo, um vasto movimento de empregos em regiões e países até então tidos como subdesenvolvidos ou periféricos, se bem que a qualidade dessas ofertas venha sendo, incisivamente, problematizada no campo acadêmico e entre os grupos de ativistas e de associações de classe.

De fato, essas transformações globais fazem com que o excedente populacional vincule-se às necessidades geradas tanto nas áreas de origem da emigração como nas de destino, compondo uma movimentação humana que acompanha o capital e a inserção das localidades na divisão social e territorial do trabalho (Harvey, 2005). Nessa perspectiva, as sistêmicas crises econômicas enfrentadas pelas "potências" dos continentes europeu e americano parecem constituir, também, o pano de fundo para que, no bojo da reestruturação produtiva vigente, o capital se desloque para espaços onde o complexo econômico e financeiro, apenas recentemente, tenha se delineado com maior envergadura, como é o caso do Brasil.

Como temos enfatizado nesta reflexão, esse movimento consolida, na sua esteira, paisagens humanas variavelmente compósitas e multiformes, traduzidas, entre os seus aspectos incomensuráveis, pelo caráter multiétnico da crescente população (IBGE, 2014) e pela diversidade da mão de obra empregada nas empresas atuantes no território brasileiro. Esses estrangeiros ${ }^{1}$, com certa regularidade, tecem relações da mais diversa ordem com a população da cidade para onde se destinam e pelas localidades por onde circulam, instituindo suas multiterritorialidades próprias (Haesbert, 2004), mas em particular nos ambientes coletivos da esfera do trabalho esses relacionamentos podem ser tensionados e depender de um conjunto de fatores para a sua recondução, o que nos incita à elaboração da seguinte problemática: de ambos os lados, isto é, entre os que chegam e os que "recebem", há um substrato de representações sociais (Moscovici, 2003), convertido em percepções, expectativas, sentimentos, atitudes, posicionamentos ideológicos, inclusive de cunho moral, que é acionado quando das situações de contato intercultural, o que pode gerar experiências paradoxais, individuais ou em grupo, de aceitação e/ou estranhamento.

Não adotaremos, nesta reflexão, as distinções semânticas entre os termos estrangeiros e imigrantes, embora reconheçamos a pertinência na diferenciação. 
Nesse caso, na estrutura empresarial, há possibilidades de (re)conhecimento da alteridade e de diálogo salutar entre profissionais de distintas origens geográficas ou, em sentido inverso, convive-se com a iminência de comportamentos intolerantes e xenófobos frente ao "outro" recém-chegado, ainda que esse "outro" mais não seja que o "mesmo" em termos de igualdade de condições, direitos, apreensões e interesses, posto que igualmente pertencente ao público interno da organização? Os princípios incrustrados na cultura organizacional e legitimados pelos fluxos comunicacionais diários podem fomentar, pela via da interculturalidade, a interação e a valorização da diversidade humana no ambiente de trabalho, sem incorrer em discursos e práticas discriminatórias acerca de nacionalidades, etnias, religiões, línguas, costumes ou qualquer outro marcador sociocultural de diferenças? São, com efeito, fundamentos institucionais que refletem ou refratam as possibilidades de diálogo?

\section{A CULTURA ORGANIZACIONAL COMO PONTO DE PARTIDA}

Diversos estudos da área das ciências sociais vêm alertando para o fato de que as médias e grandes cidades, ao se inserirem na rota do mercado mundial e dos fluxos migratórios internacionais, enfrentam o desafio de promover a convivência pacífica e democrática entre as populações que nelas habitam (Touraine, 1995; Wieviorka, 1995; García-Canclini, 2008), o mesmo desafio que, em certos microcosmos, como o da dinâmica interna empresarial, deve ser encarado de forma planejada e com a devida urgência, como alertam Sriramesh e Vercic (2003), Grunig (2011), Ferrari (2011; 2012) e outros autores do campo da Comunicação Organizacional. Essa assertiva é válida não apenas para as corporações multinacionais ou globais atuantes em territórios os mais variados e dispersos, como verificou Rosiney A. M. Weber (2004), mas também para as indústrias e empresas brasileiras que vêm empregando mão de obra estrangeira em seus negócios. Independentemente se são engenheiros alemães, portugueses, espanhóis, técnicos norte-americanos contratados para atuarem no ramo petrolífero, da construção civil ou na expansão do setor do turismo, por exemplo, ou ainda nigerianos, senegaleses, haitianos, bolivianos que passaram a compor, normalmente a custo baixo, o "chão de fábrica" de empresas de médio porte do interior de Santa Catarina, Rio Grande do Sul e São Paulo, o fomento dos vínculos comunicacionais entre sujeitos de nacionalidades distintas no "mundo do trabalho" (Antunes, 2009) coloca-se como questão central, quiçá, emergencial, em determinados casos.

Nessa linha de entendimento, faz-se necessário esclarecermos que, diferentemente da concepção epistemológica subjacente à noção de multiculturalidade, que reconhece a existência de uma miríade de culturas situada num mesmo espaço físico sem, necessariamente, haver qualquer tipo de interação entre seus membros, os estudos contemporâneos exploram a noção de interculturalidade como uma das vias para o convívio social salutar. García-Canclini (2008) acentua que esse conceito vem sendo adotado para indicar um conjunto de propostas que viabilizam o intercâmbio comunicativo entre os grupos culturais/ étnicos/nacionais, reconhecendo-se que, de fato, essas experiências podem ser entrecortadas por negociação e conflitos, que, entretanto, devem ser refletidas, reconduzidas, no intuito de assegurar o respeito mútuo. "É preciso analisar a complexidade que assumem as formas de interação e de rejeição, de apreço, discriminação ou hostilidade em relação aos outros nestas situações de assídua confrontação" (García-Canclini, 2008, p. 36).

A antipatia e/ou a aversão, não raramente, podem se converter em comportamentos hostis ou mesmo xenófobos ante aqueles que são enquadrados na categoria simbólica do "outro", do estranho indesejado, do forasteiro acusado de "roubar o nosso trabalho" ou de interrogar e transgredir as normas, os costumes e os padrões morais vigentes. Na prática, isso significa que, 


\section{ANO 11 • NÚMERO $21 \cdot 2$ - SEM. 2014 • ORGANICOM \\ CENAS DA DIVERSIDADE NO AMBIENTE EMPRESARIAL: OS ATUAIS FLUXOS MIGRATÓRIOS INTERNACIONAIS PARA O BRASIL E O DESAFIO DA INTERCULTURALIDADE}

183

inclusive no ambiente empresarial, os imigrantes tanto podem ser visivelmente reconhecidos segundo suas características individuais e de acordo com alguns atributos comuns ao grupo nacional de que fazem parte, quanto podem sofrer coerções, de forma explícita ou sutil (Wieviorka, 1995), por serem identificados como produto final de uma suposta identidade nacional ou étnica. Representados como unidades "exemplares" de uma categoria homogênea, estereotipada, portanto, correm o risco de se tornarem invisíveis perante os que relutam pela negação de sua presença no mesmo espaço, situação que certamente compromete a vitalidade do clima organizacional onde essas relações (não) se processam.

Nas empresas com diagnósticos dessa natureza, o não-reconhecimento da diversidade cultural e étnica pode retroalimentar uma atmosfera pouco favorável ao trabalho em coletividade, que prime pela saúde mental do trabalhador e pela dignidade humana. Na linha do que o Instituto Ethos (2000) já havia enfatizado no documento "Como as empresas podem (e devem) valorizar a diversidade", o combate à intolerância estimula a cooperação e a sinergia entre os profissionais de uma organização em torno dos objetivos comuns, promovendo vínculos afetivos entre os funcionários, dentro e até mesmo fora da empresa, assim como revigorando 0 relacionamento desse público interno multiface com a própria organização, que se mostra consciente de seus princípios e suas condutas. Aos inúmeros benefícios que o diálogo intercultural proporciona soma-se o fato de as empresas, heterogêneas e mais competitivas, reunirem atributos para enfrentar as turbulências que, costumeiramente, se sucedem no panorama econômico local e global, na sua íntima interconexão, adaptando-se às contingências e vulnerabilidades de diversa ordem (Ferrari, 2011).

Daí a centralidade da cultura e da comunicação institucionais como sólidos sustentáculos para o desenvolvimento e manutenção das competências em torno da comunicação intercultural nesse ambiente. 0 posicionamento democrático e não discriminatório deve se constituir como um dos valores postos em prática e legitimados na dinâmica cultural e comunicacional interna, conduzindo o exercício da aceitação e do relacionamento desprovido de preconceitos dos sujeitos também produtores de cultura e sentidos nesse cenário. Em outros termos, os estereótipos compartilhados sobre certas populações estrangeiras, se transportados para o espaço do trabalho, devem encontrar na cultura organizacional solo fértil para a sua recusa e desconstrução. Afinal, como acentuam Paulo Nassar (2000) e Marlene Marchiori (2006), a cultura das organizações deve agregar fundamentos que viabilizem o planejamento de estratégias de comunicação, de marketing, de gestão de pessoas, além das de outras áreas, que permitam a interação e a confiança nos relacionamentos internos, evitando posturas autoritárias, egocêntricas e, no caso da temática aqui tratada, etnocêntricas e preconceituosas. Cabe aos líderes da coalização dominante (Grunig, 2011) e aos profissionais responsáveis pela gestão da comunicação interna, em articulação aos demais setores, um trabalho sistemático e permanente de promoção do diálogo e diluição das possíveis fricções relacionais, muitas vezes ocasionadas por desconhecimento recíproco ou por falha nos processos informacionais.

\section{CONSIDERAÇÕES FINAIS}

Como explorado nesta reflexão, o Brasil vem despontando como destino dos fluxos de trabalhadores e outros migrantes internacionais. Esse panorama, no âmbito empresarial, sugere a composição de equipes de funcionários cujas nacionalidades podemserasmais distintas, trazendoconsigo umamplomosaico deenredoshistórico-culturais nem sempre reconhecido eaceito pelos interlocutores. A atualidade dessa questão, vale pontuar, não diz respeito apenas às empresas multinacionais ou globais que atraem seus funcionários, geralmente qualificados, tampouco se restringe àquelas em processo de internacionalização, fusão ou outro tipo de expansão dos seus negócios, como circunscrevem os estudiosos sobre o tema. Para além dessas, que nos 
parecem inevitáveis, o desafio da implantação e manutenção do diálogo intercultural também engloba as médias e grandes empresas nacionais que vêm contratando os imigrantes recém-chegados nas cidades brasileiras onde estão alocadas.

Essa nova conjuntura deve encontrar na cultura e na comunicação institucionais as bases sólidas tanto para a oferta de informações a respeito dos sujeitos que constituem o público interno quanto para promover, de forma sistemática, contínua, fraternal, o ambiente propício ao (re)conhecimento e diálogo intercultural. Para tanto, os discursos e as práticas institucionais devem incorporar esses mesmos preceitos. As políticas e técnicas de comunicação, por sua vez, atuam na realimentação desse ciclo virtuoso e no desenvolvimento de competências atreladas à comunicação intercultural na estrutura empresarial.

\section{REFERÊNCIAS}

ANTUNES, Ricardo. Adeus ao trabalho? Ensaio sobre as metamorfoses e a centralidade do mundo do trabalho. 13. ed. São Paulo: Cortez, 2009.

APPADURAI, Arjun. Dimensões culturais da globalização. Lisboa: Teorema, 2004.

AYLLÓN PINO, Bruno. Asrelações Brasil-Espanhanaperspectivada política externa brasileira(1945-2005). São Paulo: Emblema, 2006.

BAENINGER, Rosana (Org.). Imigração boliviana no Brasil. Campinas: Nepo-Unicamp, 2012.

. Notas acerca das migrações internacionais no século 21. In: BAENINGER, Rosana (Org.). Por dentro do estado de São Paulo: migrações internacionais. Campinas: Nepo-Unicamp, 2013, v. 9, p. 9-22.

BAUMAN, Zygmunt. Modernidade líquida. Rio de Janeiro: Zahar, 2003.

CASTELLS, Manuel. A sociedade em rede. Vol. I. 10. ed. São Paulo: Paz e Terra, 2007.

COGO, Denise. Haitianos no Brasil: comunicação e interação em redes migratórias transnacionais. Chasqui - Revista Latinoamericana de Comunicación, v. 125, p. 23-32, 2014.

DESIDÉRIO, Edilma. Migração e políticas de cooperação: fluxos entre Brasil e África. In: ENCONTRO NACIONAL SOBRE MIGRAÇÃO, IV, 16-18 nov. 2005, Rio de Janeiro, p. 1-23. Anais... Disponível em: <http://www.abep.nepo.unicamp. br/docs/anais/ outros/4EncNacSobreMigracao/SCl-3.pdf>. Acesso em: 03 jul. 2014.

DWYER, Tom. A China e os desafios das ciências sociais brasileiras no cenário do mundo em processo de globalização. In: RIBEIRO, Gustavo L. et al. (Org.). As ciências sociais no mundo contemporâneo: revisões e prospecções. Brasília: Letras Livres e Editora da UnB, 2011. p. 211-224.

FERRARI, Maria A. Cenário latino-americano da comunicação e de relações públicas. In: GRUNIG, James E.; FERRARI, Maria Aparecida; FRANÇA, Fábio (Org.). Relações públicas. teoria, contexto e relacionamentos. 2. ed. São Paulo: Difusão, 2011. 
Gestão da comunicação intercultural nas organizações brasileiras em tempos de globalização. Comunicologia, v. 1, p. 178204,2012. Disponível em: <http://portalrevistas.ucb.br/index.php/RCEUCB/article/viewArticle/3735>. Acesso em: 23 jun. 2014.

GARCÍA-CANCLINI, Néstor Diferentes, desiguais e desconectados: mapas da interculturalidade. Rio de Janeiro: UFRJ, 2008.

GRUNIG, James E. Uma teoria geral das relações públicas: quadro teórico para o exercício da profissão. In: GRUNIG, James E.; FERRARI, Maria Aparecida; FRANÇA, Fábio. Relações públicas: teoria, contexto e relacionamentos. 2. ed. São Caetano do Sul, SP: Difusão, 2011.

HAESBERT, Rogerio. O mito da desterritorialização: do "fim dos territórios" à multiterritorialidade. Rio de Janeiro: Bertrand Brasil, 2004.

HARVEY, David. A produção capitalista do espaço. São Paulo: Annablume, 2005.

IBGE -Instituto Brasileiro de Geografia e Estatística. Estimativas da população dos municípios brasileiros com data de referência em $1^{\underline{o}}$ de julho de 2014. Disponível em: <http://www.ibge.gov.br/home/presidencia/noticias/ pdf/analise_estimativas_2014. pdf>. Acesso em: 02 de set. 2014.

INSTITUTO ETHOS. Como as empresas podem (e devem) valorizar a diversidade. São Paulo: Instituto Ethos, 2000.

LAMPREIA, Luiz F. Atualidade. In: DONATO, Hernâni; LAMPREIA, Luiz F. Câmara Portuguesa de Comércio no Brasil. O investimento português no Brasil: histórico e atualidade. São Paulo: Nova Bandeira, 2003.

LANG, Alice B. da S. G.; CAMPOS, Maria C. S. de S. Comunidade portuguesa em São Paulo - Anos 2010. Cadernos CERU, v. 3, n. 2 , 2012, p. 103-126. Disponível em: <http://www.revistas.usp.br/ceru/article/view/56880/59861>. Acesso em: 14 ago. 2014.

MARCHIORI, Marlene. Cultura e comunicação organizacional: um olhar estratégico sobre a organização. São Caetano do Sul, SP: Difusão, 2006.

MOSCOVICI, Serge. Representações sociais: investigações em psicologia social. Rio de Janeiro: Vozes, 2003.

NASSAR, Paulo (Org). Comunicação interna: a força das empresas. Vol. 1. São Paulo: Aberje Editorial, 2003.

OLIVEIRA, Ana C. V. de; MOREIRA, Paula G. Os imigrantes ilegais da Colômbia e do Haiti no Brasil: considerações do ponto de vista da segurança internacional. Mural Internacional, v. 4, n. 2, 2013, p. 63-71. Disponível em: <http://www.e-publicacoes.uerj. br/index.php/muralinternacional/article/view/8370/6500 >. Acesso em: 10 jul. 2014.

PAIVA, Odair da C. Territórios da migração na cidade de São Paulo: entre a afirmação e negação da condição migrante. Ideias, Instituto de Filosofia e Ciências Humanas, Universidade Estadual de Campinas, a. 2, n. 2, p. 13-30, 2011.

PATARRA, Neide L. Migrações internacionais de e para o Brasil contemporâneo: volumes, fluxos, significados e políticas. São Paulo em Perspectiva, v. 19, n. 3, p. 23-33, jul./set. 2005. 
PERES, Roberta G.; BAENINGER, Rosana. Conexão Brasil-China: primeiras reflexões sobre um fluxo migratório multifacetado. In: BAENINGER, Rosana; DEDECCA, Claudio S. (Org.). Processos migratórios no Estado de São Paulo: estudos temáticos, v. 10. Campinas: Nepo/Unicamp, 2013. p. 565-570.

SALES, Teresa. Imigrantes estrangeiros, imigrantes brasileiros: uma revisão bibliográfica e algumas anotações de pesquisa. Revista Brasileira de Estudos de População, Campinas, v. 9, n. 1, p. 50-64, jan./jul. 1992

SASSEN, Saskia. Sociologia da globalização. Porto Alegre: Editora Artmed, 2010.

SOUCHAUD, Sylvain; FUSCO, Wilson. Diagnóstico das migrações internacionais entre Brasil, Paraguai e Bolívia. In: CENTRO DE GESTÃO E ESTUDOS ESTRATÉGICOS. Populações e políticas sociais no Brasil: os desafios da transição demográfica e das migrações internacionais. Brasília: Centro de Gestão e Estudos Estratégicos, 2008. p. 266-293.

SOUZA, Ismara I. de. Espanhóis. história e engajamento. São Paulo: Companhia Editora Nacional, 2006.

SRIRAMESH, Krishnamurthy; VERCIC, Dejan (Ed.). The global public relations handbook:theory, research, and practice. Nahwah, NJ: Lawrence Erlbaum, 2003.

TARRIUS, Alan. La mondialisation par le bas. les nouveaux nomades de l'économie souterraine. Paris: Éditions Balland, 2002.

TOURAINE, Alain. 0 racismo hoje. In: WIEVIORKA, Michel. Racismo e modernidade. Venda Nova, Portugal: Bertrand Editora, 1995. p. 25-43.

WALLERSTEIN, Immanuel. World-system analysis. London: Duke University Press, 2004.

WEBER, Rosiney A. M. A comunicação intercultural no ambiente de trabalho. 2004. 82 f. Dissertação (Mestrado em Engenharia de Produção) - Programa de Pós-graduação em Engenharia de Produção, Universidade Federal de Santa Catarina, Florianópolis, 2004. Disponível em: <http://repositorio.ufsc.br/xmlui/ handle/123456789/87975>. Acesso em: 26 jul. 2014.

WIEVIORKA, Michel. Racismo e modernidade. Venda Nova, Portugal: Bertrand Editora, 1995.

Artigo recebido em 08.09.2014 e aprovado em 30.10.2014. 